\title{
JAPONSKI ZAPIS SLOVENSKIH ENOZLOŽNIH IZREK: TRANSKRIPCIJA IN FONOLOŠKE OMEJITVE PRI PRENOSU GLASOVNE PODOBE
}

\author{
Nina GOLOB \\ University of Ljubljana \\ nina.golob@ff.uni-lj.si
}

\begin{abstract}
Japanese language like any natural language ${ }^{1}$ is built of a native lexicon and a borrowed one. The latter is, due to its extent of diachronic phonological assimilation into a borrowing language, further devided into sublexica. Some of the phonological patterns exhibited by borrowed sublexica are common to several classes while others are exceptional to only one, and are as such organized in a subset relation. The article reviews phonological patterns of recently borrowed lexicon (foreign words) in Japanese within the phonetic-phonological loanword framework, and discusses the patterns and possible workouts for Slovene monosyllabic words entering into Japanese. Attention is also paid to the discrepancy between transcription, phonological patterns and phonetic forms, and to the influence of source language transcription onto the borrowing process.
\end{abstract}

Keywords: Japanese, transcription, Slovene monosyllabic words, phonological constraints, phonetics

\section{Povzetek}

Japonščina je tako kot vsak jezik ${ }^{1}$ sestavljena iz jedrnega in prevzetega besedja. Slednji je zaradi diahronega prevzemanja razdeljen na več podskupin, katerih asimilacija $\mathrm{v}$ ciljni jezik podskupinam oblikuje specifične fonološke značilnosti. Nekatere so si med seboj podobne, druge so edinstvene eni podskupini, zato so podskupine ponavadi $v$ hierarhičnem odnosu. Članek obravnava fonološke značilnosti novejše prevzetih besed $\mathrm{v}$ japonščini $\mathrm{v}$ splošno priznanem fonetično-fonološkem teoretičnem okvirju o prevzemanju besed ter skozi fonetiko razpravlja o vzorcih in možnih rešitvah pretvorbe slovenskih enozložnih besed oz. njihovih izrek v japonščino. Nekaj pozornosti članek namenja tudi odnosu med zapisom, fonološkim vzorcem in fonetično realizacijo ter vplivu izvornega zapisa na proces prevzemanja.

Ključne besede: japonščina, transkripcija, slovenske enozložne izreke, fonološke omejitve, fonetika

\footnotetext{
1 'The lexical stock of any given language includes words borrowed from other languages' (Poplack and Sankoff 1984: 99). V prevodu: 'Besedje kateregakoli jezika vsebuje besede, prevzete iz drugega jezika'.
}

Acta Linguistica Asiatica, 4(3), 2014.

ISSN: 2232-3317, http://revije.ff.uni-lj.si/ala/

DOI: 10.4312/ala.4.3.83-92 


\section{Uvod}

\subsection{Stratifikacija japonskega besedja}

Notranja stratifikacija besedja je poznana večini jezikom, katerih slovnice so vsaj deloma raziskane. Jeziki so osnovani na t.i. jedrnem besedju, ki se mu pridružujejo druge besedne skupine, na primer prevzete besede, tujke, asimilirane besede in druge. ${ }^{2} \mathrm{Te}$ ponavadi nosijo oznako o svojem izvornem jeziku ter se na njegovi osnovi tudi grupirajo. Znotraj skupin kažejo podobne slovnične vzorce pri omejitvah morfemskih struktur, pri kombinatoriki morfemov in morfofonemskih spremembah. Zato je poznavanje in razumevanje fonoloških vzorcev, na osnovi katerih je predlagana stratifikacija, "ključnega pomena pri analizah /japonske/ fonologije, ki hkrati spodbuja razmišljanje o fonološki organizaciji jezika in o njegovi slovnici na splošno" (Ito in Mester, v Tsujimura 1999: 62).

Japonsko besedje je v splošnem razdeljeno na jedrno besedje yamato (大和言葉 yamatokotoba) in prevzeto besedje ali 借用語 syakuyoogo (Slika 1).

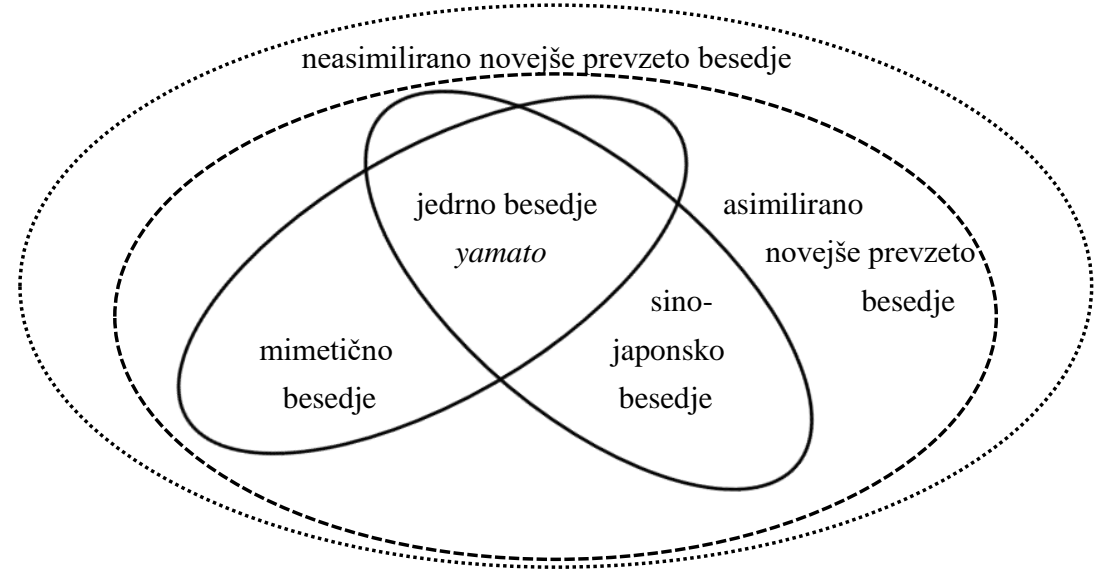

Slika 1: Stratifikacija japonskega besedja in hierarhičnost med skupinami (Ito in Mester 1993).

Leksikalna stratifikacija, ki sta jo predlagala Ito in Mester $(1993,1995)$ in temelji na fonoloških zakonitostih besed, prevzeto besedje nadalje razdeli na tri osnovne skupine: sino-japonsko besedje (漢語 kango), novejše prevzeto besedje (洋語 yoogo oz. 外来語 gairaigo) $^{3}$ in mimetično besedje (擬声語 giseego in 擬態語 gitaigo), pri čemer ima

\footnotetext{
${ }^{2} \mathrm{~V}$ slovenski jezikoslovni terminologiji nejedrno besedje ločimo na tujke, ki po definiciji na ta ali oni način ohranjajo izvirno formalno podobo in so novemu jeziku prilagojena le do določene mere, ter na izposojenke, ki se oblikoslovno, pravopisno in glasoslovno prilagodijo sistemu sprejemajočega jezika (Toporišič 2000, Snoj 2005). Ta razdelitev v slovenščini vseeno ni povsem očitna; tako so med tujkami tudi iz francoščine prevzeta embalaža, iz angleščine prevzeti punč in iz japonščine prevzeti judo.

${ }^{3} \mathrm{~V}$ nasprotju s terminom 洋語 yoogo, s katerim poimenujemo besede, prevzete predvsem iz angleščine in drugih evropskih jezikov, je termin 外来語 gairaigo med nekaterimi jezikoslovci
} 
novejše prevzeto besedje podkategoriji asimilirano novejše prevzeto besedje in neasimilirano novejše prevzeto besedje (Ito in Mester 1999). Odnos teh fonoloških sistemov je prikazan s sliko 1.

Paradis 1996, Jacobs \& Gussenhoven 2000, Shinohara 2004, LaCharité \& Paradis 2005 zagovarjajo hipotezo, da vključevanje poteka po fonoloških merilih ciljnega jezika oziroma v njegovem produkcijskem procesu. Paradis 1996 navaja, da nove besede v jezik uvajajo dvojezično govoreči, ki odlično dojemajo izvorni jezik besed in preslikavajo njihove površinske oblike (surface forms) v temeljne fonološke oblike (underlying forms) ciljnega jezika. Te se s pomočjo fonološke slovnice ciljnega jezika oblikujejo v njegove površinske oblike. Hkrati priznavajo, da se v ciljnem jeziku oblikujejo posebni mehanizmi, ki sodelujejo samo pri fonološkem uravnavanju prevzetih besed in jih $\mathrm{v}$ fonološki slovnici jedrnega besedja ni moč zaznati. Eden takšnih mehanizmov v japonščini je samoglasniško vstavljanje ali epenteza ${ }^{4}$, ki ga zasledimo v besedah kot so バブル (baburu, slov. razcvet, orig. angl. bubble), シフト (shifuto, slov. sprememba, orig. angl. shift), コルク (koruku, slov. pluta, orig. port. kurk), イクラ (ikura, slov. ikra lososa, orig. rus. ikra), トリオ (torio, slov. trio, orig. it. trio) idr. .

Opredeljavanje nekaterih mehanizmov fonološke slovnice kot mehanizmov, ki so veljavni izključno za prevzeto besedje, je problematično z vidika razlage, kdaj in pod kakšnimi pogoji se takšni mehanizmi oblikujejo. Temu se nekateri avtorji izognejo z iskanjem rešitev $\mathrm{v}$ fonetični razlagi, kjer so značilnosti prevzemanja definirane $\mathrm{v}$ percepcijskem procesu (Silverman 1992, Peperkamp \& Dupoux 2003, Peperkamp 2005). Akustičnemu signalu izvornega jezika so najprej izbrane najbližje fonetične kategorije ciljnega jezika, in šele nato sledi preslikava $\mathrm{v}$ globinsko ali fonološko podstavo ciljnega jezika. T.i. percepcijska asimilacija je psiholingvistični efekt oz. težnja slušatelja, da akustični signal (izgovorjeno) sprejema preko fonološkega 'filtra' maternega jezika, še posebej $\mathrm{v}$ primerih, ko tip akustičnega signala ne obstaja $\mathrm{v}$ slušateljevemu maternemu jeziku (Halle et al. 1998, Pepperkamp \& Dupoux 2003). Dupoux et al. 1999 v svoji raziskavi pokažejo, da japonski govorci s težavo razločijo med zanje fonološko nesprejemljivim soglasniških zaporedjem $\left(\mathrm{VCCV}^{5}\right)$ in glasovnim zaporedjem, kjer je med soglasnika dodan samoglasnik /u/ (VC[u]CV).

Smith (2006) sicer opozarja, da razlaga vstavljenih samoglasnikov (epenteze) na percepcijskem nivoju pomeni, da bi morali biti v globinski podstavi vsi samoglasniki

uporabljen za vso prevzeto besedje, ki ni sino-japonsko, torej tudi za besede iz jezikov ryukyu (npr. ゴーヤー gooyaa, slov. grenka buča), ainu (npr. ラッコ rakko, slov. morska vidra) idr. Tako prva kot druga vrsta prevzetih besed je zapisana $\mathrm{v}$ katakani (tj. enem izmed zlogovnih zapisov japonščine).

${ }^{4}$ Samoglasniško vstavljanje se pojavlja samo v novejše privzetem besedju v japonščini in se usklajuje z japonsko fonotaktiko in zlogotvornimi procesi. $\mathrm{V}$ preostalih besedjih (glej podpoglavje 1.1) je značilen njemu nasprotni pojav, tj. soglasniški izpad ali elizija, (McCawley 1968), ki se pojavlja v kavzativnih glagolskih oblikah させる (saseru), kot na primer 待たせる (mataseru, slov. pustiti čakati) osnovnega glagola 待つ (matsu, slov. čakati).

${ }^{5} \mathrm{~V}$ predstavlja samoglasnik (angl. vowel), C pa soglasnik (angl. consonant). V omenjenem soglasniškem zaporedju je izvzeto zaporedje, ko je prvi soglasnik moraični nosnik /N/. 
enakovredni, kar pa je v svojem delu o naglasnih pravilih iz francoščine prevzetih besed ovrgel že Shinohara (2000), kasneje tudi Kubozono (2006) za novejše prevzeto besedje v splošnem.

Kljub dvema nasprotujočima se hipotezama pa nihče izmed zgoraj omenjenih avtorjev ne trdi, da je slovnica prevzetih besed oblikovana izključno samo na fonetični oz. samo na fonološki ravni. Zato se zdi najmanj problematičen kombinirani teoretični okvir, v katerem prevzemanje besed poteka v interakciji izvornega jezika (jezika dajalca) in ciljnega jezika (jezika prejemnika), njunih fonologij in pod vplivom univerzalnih fonetičnih teženj (Yip 2002, Kenstowicz 2004, Smith 2006 idr.).

\subsection{Prevzemanje besed $v$ japonščini}

Kubozono (2006) tako predlaga, da se fokus raziskav o fonologiji prevzetih besed pomakne na način interakcije med fonetično (percepcijo) in fonološko ravnijo. Ta naj bi bil še posebno zanimiv v prozodiji, predvsem pri naglaševanju.

$\mathrm{V}$ japonščini ${ }^{6}$ prepoznavamo tonemsko naglaševanje $\mathrm{z}$ izmenjujočimi se visokimi in nizkimi toni. Naglasno mesto je arbitrarno določeno na zadnji moraični enoti (in ne $\mathrm{zlogu}$ ! ${ }^{7} \mathrm{z}$ visokim tonom, besede pa so lahko naglašene, $\mathrm{tj}$. $\mathrm{z}$ naglasnim naglasnim mestom, ali pa nenaglašene, $\mathrm{tj}$. brez naglasnega mesta.

Znano je, da japonsko jedrno besedje stremi k nenaglašenosti (Haraguchi 1991, Shibata 1994, Kubozono 1996, Shinohara 2000). Obenem je za druga besedja dolgo veljalo, da so besede povečini naglašene, naglasno mesto pa praviloma pripada tretji moraični enoti od konca besede (več o tem v nadaljevanju). Kubozono (2006) je v svoji raziskavi, kjer je natančneje analiziral naglašenost po besednih skupinah, ponovno potrdil zgornjo trditev o večinski nenaglašenosti jedrnega besedja. Ugotovil je, da je več kot $70 \%$ jedrnega besedja nenaglašenega, kar je precej več kot pri sino-japonskem besedju, kjer je približno polovica besed nenaglašenih, oz. novejše prevzetem besedju, kjer je nenaglašenega besedja manj kot 10\% (ibid. ). Vendar pa je hkrati na izsledkih o pravilih naglaševanja japonskih prevzetih besed v nasprotju s predhodnjimi raziskavami (Akinaga 1985, Shibata 1994) zaključil, da ob upoštevanju specifičnosti zlogovanja (visoka pojavnost težkih, dvomoraičnih zlogov) in naravi samoglasnikov (visoka pojavnost vstavljenih samoglasnikov) v prevzetih besedah naglaševanje le-teh ni tako izjemno in se ne razlikuje od vzorcev naglaševanja japonskega jedrnega besedja. Kot primer navaja štirimoraične prevzete besede ${ }^{8}$, ki se med seboj razlikujejo v številu zlogov oz. glasovni sestavi ${ }^{9}$ na naslednje skupine (Kubozono 2006).

\footnotetext{
${ }^{6}$ Normirani govor po pravilih državne organizacije NHK (Nippon Hoosoo Kyookai), ki opravlja radijske in televizijske dejavnosti.

${ }^{7} \mathrm{Za}$ japonsko jedrno besedje je značilno, da je v veliki večini sestavljeno iz lahkih, enomoraičnih zlogov (Martin 1987, Frellesvig 1995).

${ }^{8}$ Rezultati analize 700 krajevnih imen prevzetih v japonščino (Kubozono 2006).

${ }^{9}$ Kubozono (2006) pri opisu uporablja kratici "L" in "H". L pomeni light syllable ali po slovensko odprti, kratki oz. enomoraični zlog (zgoraj označen s "K"). H pomeni heavy syllable ali po
} 
I. skupina: KKKK

アメリカ (amerika, slov. ZDA), ドリフト (dorifuto, slov. razprševanje), リスト

ラ (risutora, slov. prestrukturiranje), キリスト (kirisuto, slov. Kristus).

II. skupina: DKK

キャンセル (kyanseru, slov. odpoved), アイドル (aidoru, slov. idol), サービス (saabisu, slov. storitev), ライバル (raibaru, slov. tekmec)

III. skupina KDK

スカート (sukaato, slov. krilo), コロッケ (korokke, slov. kroket), ストーブ (sutoobu, slov. peč), バカンス (bakansu, slov. počitnice)

IV. skupina KKD

ウイスキー (wisukii, slov. viski), ホルモン (horumon, slov. hormon), バリカン (barikan, slov. strižnik las), ギャラリー (gyararii, slov. galerija)

V. skupina: DD

パーティー (paathii, slov. zabava), バーゲン (baagen, slov. razprodaja), ジャン

パー (janpaa, slov. jopica), デッサン (dessan, slov. skica)

Nenaglašene besede so najbolj zastopane v skupini A (več kot 50\%), v preostalih skupinah je opazen trend padanja zastopanosti nenaglašenih besed in sicer s pomikom težkega oziroma dolgega zloga (D) proti koncu besede (od skupine II. do skupine V.; ibid. 2006). Poleg sestave zlogov v privzeti besedi Kubozono pri vplivih na prisotnost oziroma odsotnost naglasnega mesta omenja tudi naravo samoglasnikov, pri čemer vstavljeni samoglasniki (pojav epenteze), še posebej če se nahajajo v zadnjem zlogu besede, določajo prisotnost naglasnega mesta (Kubozono 1996). Tako so na primer besede ストレス (sutoresu, slov. stres, orig. angl. stress), トラブル (toraburu, slov. težava, orig. angl. trouble), マイルド (mairudo, slov. blag, orig. angl. mild), ki vsebujejo vstavljeni samoglasnik $\mathrm{v}$ zadnjem zlogu, naglašene, besede brez vstavljenega samoglasnika ali z vstavljenim samoglasnikom na začetku besede, kot na primer ステ レオ (sutereo, slov. stereo, orig. angl. stereo), イタリア (itaria, slov. Italija, orig. it. Italia), ウクレレ (ukurere, slov. ukulele, orig. hawaiian ukulele) pa nenaglašene.

\section{Novejše prevzeto besedje $v$ japonščini: slovenske enozložne izreke in proces prevzemanja}

Kompleksnost prenosa besed $\mathrm{v}$ japonščino, ki vključuje procese tako na ravni posameznih glasov, fonotaktični ravni kot tudi na prozodični ravni nam ob razlikah med slovenščino in japonščino nakazuje, da se je za začetek smotrno omejiti le na enozložne besede izvornega jezika.

slovensko dolgi, dvomoraični zlog, ki je lahko po glasovni strukturi odprti ali zaprti (zgoraj označen z "D"). Kratici sem namerno zamenjala s slovenskimi, da ne prihaja do asociacij z oznakami high ("H") in low ("L”) za višino tona v tonemskem naglaševanju. 
Fonetična in fonološka primerjava posameznih glasov japonščine in slovenščine je podrobno opisana v Golob [v pripravi], kjer je omenjen tudi glasovni prenos iz enega v drug jezik. Tako se bomo v tem delu najprej osredotočili na vrste glasovnih nizov enozložnih besed $\mathrm{v}$ izvornega jezika in rezultate prenosa teh nizov v ciljnem jeziku. Naposled bomo razpravljali še o naglašenosti in mestu naglasa v izbranih /morebitno/ privzetih besedah $\mathrm{v}$ japonščini.

\subsection{Glasovni nizi in fonotaktične omejitve}

V slovenščini je raznolikost glasovnih nizov zelo velika, precej večja kot v japonščini, katera dovoljuje predvsem izmenjujoča si samoglasniška in soglasniška zaporedja. Zaradi svoje 'revnosti' pri glasovni kombinaciji so se v japonščini izoblikovali številni mehanizmi, ki na diahroni ravni sodelujejo pri prevzemanju besed iz jezikov, ki so v glasovnih nizih bogatejši od nje.

Eden takšnih mehanizmov je zgoraj omenjeno samoglasniško vstavljanje ali epenteza (glej odsek 1.2), ko zaradi svojih fonotaktičnih omejitev ciljni jezik v glasovno zaporedje vstavlja segmente, ki so v jeziku praviloma najmanj vsiljivi, fonološko neoznačeni in v zaznavi skorajda nični (Hirayama 2003). Takšen segment v japonščini je visok, nezaokrožen in precej centraliziran samoglasnik /u/, ki je med petimi japonskimi samoglasniki najmanj izstopajoč, najbolj dovzeten za izgubo zvenečnosti (Lovins 1975), fonetično zelo kratek (Han 1962) ter nase zelo poredko pritegne naglas (Yoshida 2006). Sledita mu samoglasnika /i/ in /o/, katerih pojavnost pa je kontekstualno precej omejena (Shoji \& Shoji 2014).

\subsection{Struktura enozložnih izrek v izvornem jeziku}

Zlog je izgovorna enota iz zlogotvornega glasu ali iz zlogotvornega glasu in enega ali več soglasnikov, ki tvori besedo ali del besede. Zlogotvorni glas je jedro zloga (nukleus) in je ponavadi samoglasniški. Soglasnik ali več soglasnikov pred jedrom se imenujejo vzglasje (onset, tudi nastop), tisti za jedrom pa izglasje (koda). Oboji so poljubni, medtem ko je jedro obvezno. Zlogi brez izglasja se imenujejo odprti zlogi, zlogi z njim pa zaprti zlogi.

V slovenščini poznamo odprte zloge (npr. tla, zel) in zaprte zloge (npr. strop, smet), takšne z vzglasjem (npr. vol, čin) ali pa brez (npr. as, avt). Poleg tega je lahko jedro zloga po strukturi kratko ali pa dolgo. ${ }^{10}$ Enozložnih izrek, sestavljenih le iz jedra skorajda ne poznamo; izjema je na primer dvomoraični medmet au.

(1) slov. au $\rightarrow$ jap. アウ (au)

Druge slovenske izreke, ki bi v japonščini ohranile glasovno strukturo, so še zlogi z enoglasnim vzglasjem (2) in/ali zlogi z nosnikom /n/ v izglasju (3).

${ }^{10}$ Potrebno je paziti na razliko med fonološko in metrično dolžino. 
(2) slov. to, pav, lev, zel $\rightarrow$ jap. ト (to), パウ (pau), レウ (reu), ゼウ (zeu)

(3) slov. on, in, ton, čin $\rightarrow$ jap. オン (on), イン (in), トン (ton), チン (chin)

Preostale enozložne izreke imajo kompleksnejše soglasniške strukture, ki pri prenosu v japonščino zahtevajo vstavitev enega ali več samoglasnikov ter nekatere druge prilagoditve.

Soglasniška zaporedja v vzglasju so podvržena samo epentezi, izbor vstavljenega samoglasnika (ali več teh) pa je odvisen predvsem od njegovega vpliva na predhodnji soglasnik (več v zadnjem odstavku odseka 2.1).

(4) slov. stroj, kraj, zmaj, klovn $\rightarrow$ jap. ストロイ (sutoroi), クライ (kurai), ズマイ (zumai), クローン (kuroon)

Glasovna struktura izglasja pri prevzemanju sproži različne mehanizme glede na vrsto in število soglasnikov v izglasju. Z izjemo nosnika /n/, ki ustreza japonskemu moraičnemu nosniku (glej primere (3)), ostali zvočniki ter nezvočniški priporniki v izglasju za svojo realizacijo potrebujejo vstavljeni samoglasnik.

(5) slov. bor, šal, dom, gaz, ples $\rightarrow$ jap. ボル (boru), シャル (sharu), ドム (domu), ガス* $\left(\text { gasu }^{*}\right)^{11}$, プレス (puresu)

Slovenski zlitniki in zaporniki, ki sami sestavljajo izglasje, poleg vstavljenega samostalnika sprožijo tudi soglasniško podvojitev.

(6) slov. trop, vid, smet, zvok, muc, rob $\rightarrow$ jap. トゥロップ (turoppu), ヴィット* $\left(\right.$ vitto $\left.^{*}\right)$, スメット (sumetto), ズヴオック (zuvokku), ムッツ (muttsu), ロップ* $\left(\right.$ roppu* $\left.^{*}\right)$

$\mathrm{V}$ primerih, ko so zlitniki ali zaporniki v izglasju v kombinaciji s drugimi soglasniki, do soglasniškega podvojevanja ne pride.

(7) slov. hrošč, cink, past, lump, drozg, žvižg $\rightarrow$ jap. フロシュチュ(furoshuchu), ツィンク $(t \operatorname{sinku})$, パスト (pasuto), ルンプ (runpu), ドロスク* (dorosuku*), ジュヴィシュク* (juvishuku*)

\subsection{Naglasna pravila}

Pri prenosu izreke iz enega v drugi jezik se prenesene fonetične značilnosti v ciljnem jeziku ne izražajo nujno znotraj iste domene kot $v$ izvornem. In ker je tudi tip naglaševanja $v$ japonščini drugačen kot na primer $v$ angleščini, iz katere je prevzeta večina besed, japonščina fonetično uskladitev uravnava na več različnih nivojih (glasovnem, ritmičnem,...) ter hkrati v domeni naglaševanja ustvarja lastna pravila (npr. jap. ドラマ d プama, slov. drama, orig. angl. drama). Tako so besede, ki pri prenosu ne spreminjajo glasovnega sestava, torej ne vsebujejo vstavljenega samoglasnika,

\footnotetext{
${ }^{11}$ Vsi spodnji primeri, označeni z zvezdico, izražajo primer odzvenevanja zvenečega nezvočnika v izglasju (več o tem v odseku 2.4).
} 
podvojenega zapornika oz. pripornika ali pa moraičnega nosnika, praviloma nenaglašene. Vse druge pa imajo naglasno mesto, ki je pri daljših besedah na tretji moraični enoti, šteto od zadaj, oziroma na njeni predhodnici, če je tretja moraična enota t.i. posebna moraična enota (tj. moraični nosnik, moraični pripornik ali zapornik, moraični samoglasnik). Tukaj je potrebno dodati, da se vstavljeni samoglasnik, še posebej, če je to /u/, izogiba naglasnemu mestu.

Iz zgornjega lahko sklepamo, da bodo enozložne slovenske izreke, ki v japonščini postanejo dvo-, tro- in večmoraične, praviloma imele naglasno mesto.

(8) slov. lev, bor, klet, bob, ščit, dolg, dlan $\rightarrow$ jap. レウ (rêu), ボル (boru), クレ ット (kurêtto), ボップ (boppu), シチワッ (shichitto), ドーク (dooku), ドラフン (dorảan)

Izjema so le besede z jedrom /ai, oi, ui/ brez izglasja in z vzglasjem, kjer sta največ sva soglasnika, ki morata biti nezvočnika.

(9) slov. maj, boj, fuj, *kraj, *stroj $\rightarrow$ jap. マイ (mai), ボイ (boi), フイ (fui), *クライ (*kürai), *ストロイ (*sutoroi)

\subsection{Vloga zapisa izvornega jezika}

Ob zgoraj naštetih primerih dva fonološka pojava v slovenščini, to sta odzvenevanje in palatalizacija, pri prenosu ostajata nedorečena in zahtevata dodatne razprave. Oba se nanašata na izglasje zloga (v primeru večzložnih besed na izglasje v zadnjem zlogu besede), kjer prihaja tudi do razlik med zapisom ter izreko.

Odzvenevanje (angl. devoicing) zvenečih nezvočnikov v jeziku, ki ima tako zveneče kot nezveneče nezvočnike, se značilno pojavlja na koncu neke prozodične domene (Selkirk 1978, 1986) in je značilno /tudi/ za slovenščino (Toporišič 2000, Ferme 2006). Tako so glasovi v izglasju naslednjih enozložnih besed v izreki nezveneči ${ }^{12}$.

(10) slov. vrag, hrib, pod, gozd $\rightarrow$ jap. ヴラック(vurakku), フリップ(furippu), ポット (potto), ゴスト (gosuto)

Palatalizacija izglasnih zvočnikov je diahroni fonološki proces, ki razloži nastanek trdonebnih pripornikov. Ta ne zadeva zvočnikov /n, 1, r/, katerih palataliziranost izginja ${ }^{13}$ in se je v izreki (npr. val - valj) ne zazna več (Toporišič \& Reindl 2010). Tako palatalizacijo, ki je nakazana v izglasju naslednjih enozložnih besed, pri prenosu v japonščino lahko enostavno spregledamo.

(11) slov. panj, valj $\rightarrow$ jap. パン (pan), ヴァル (varu)

\footnotetext{
${ }^{12} \mathrm{~S}$ čimer se izognemo tako podvojevanju zvenečih zapornikov kot tudi pojavitvi dveh zvenečih nezvočnikov v isti besedi, ki so v japonščini fonotaktično nezaželjeni (Kubozono et al. 2009).

${ }^{13} \mathrm{~V}$ zapisu se še vedno ohranja črka $\mathrm{j}$ za nosnikom /n/ in jezičnikom /1/, medtem ko se je za jezičnikom /r/ skozi zgodovino izgubila.
} 


\section{Zaključek}

Članek obravnava fonološke značilnosti novejše prevzetih besed $v$ japonščini ter razpravlja o možnih rešitvah pretvorbe slovenskih besed oz. njihovih izrek v japonščino. Kljub temu, da se omejuje na enozložne besede izvornega jezika, obravnava vse glavne fonološke procese, ki sodelujejo pri prenosu, seveda pa je pričakovati, da bodo kombinacije teh procesov v primeru večzložnih besed še težje. Nekatere bodo celo dopuščale več možnih glasovnih podob v ciljnem jeziku. Te so lahko posledica razlik med zapisom in izreko v izvornem jeziku, katerih problematika je nakazana v zadnjem delu članka.

\section{Dodatna opomba avtorice}

Znano je, da v nekaterih izbraževalnih programih na Japonskem transkripcijo uporabljajo kot pomoč pri branju tujejezičnih tekstov. Takšen pedagoški pristop k usvajanju tujejezičnega glasovnega repertoarja se zdi popolnoma zgrešen. Tokratni članek je namenjen izključno razpravi o vzorcih in možnih rešitvah pretvorbe slovenskih enozložnih besed oz. njihovih izrek v primeru prevzemanja le-teh v japonščino.

\section{Literatura}

Akinaga, K. (1985). Kyōtsūgo no akusento (Naglas standardne japonščine). V NHK Nihongo hatsuon akusento jiten (Izgovarjava japonskega jezika in slovar naglaševanja). Tokio: Nihon Hōsō Shuppan Kyōkai.

Dupoux E., Y. Kakehi, C. Hirose, C. Pallier in J. Mehler. (1999). Epenthetic vowels in Japanese: A perceptual illusion? V Journal of Experimental Psychology: Human Perception Performance 25, pp. 1568-1578.

Ferme, A. (2006). Obstruent devoicing and voice assimilation in Slovene. Folia Linguistica 40(3-4), pp. 191-205.

Frellesvig, B. (1995). A case study in diachronic phonology: The Japanese onbin sound changes. Aarhus University Press.

Fukazawa, H., M. Kitahara in M. Ota (1998). Lexical Stratification and Ranking Invariance in Constraint-based Grammars. V C. Gruber, D. Higgins, K.S. Olson \& T. Wysocki (eds.). CLS34: ThePanels, pp. 47-62.

Hallé P., J. Segui, U. Frauenfelder in C. Meunier. (1999). Processing of illegal consonant clusters: A case of perceptual assimilation? V Journal of Experimental Psychology: Human Perception Performance 24, pp. 592-608.

Han, M. S. (1962). The feature of duration in Japanese. The study of sounds 10, pp. 65-80.

Haraguchi, Sh. (1991). A theory of stress and accent. Studies in Generative Grammar 37. Dordrecht \& Providence, RI: Foris Publications.

Hirayama, M. (2003). Contrast in Japanese vowels. Toronto Working Papers in Linguistics 20, pp. $115-132$.

Ito, J. in A. Mester (1999). The phonological lexicon. V Tsujimura, N. (ed.). The Handbook of Japanese Linguistics. Oxford: Blackwell, pp. 62-100.

Jacobs, H. in C. Gussenhoven (2000). Loan phonology: Perception, salience, the lexicon and OT. V J. Dekkers, F. van der Leeuw in J. van de Weijer (Ur.). Optimality Theory: Phonology, Syntax, and Acquisition. Oxford University Press, pp. 193-209.

Jurgec, P. (2008). Novejše besedje s stališča fonologije: primer slovenščine. Doktorska dizertacija. Ljubljana: Univerza v Ljubljani.

Kawahara, S., K. Nishimura in H. Ono (2003) Unveiling the unmarkedness of Sino-Japanese. V Japanese/Korean Linguistics 12: 140-151. Stanford: CSLI.

Kawahara, S. (2008). Phonetic naturalness and unnaturalness in Japanese loanword phonology. Journal of East Asian Linguistics, Vol 17 (4), pp. 317-330.

Kenstowicz, M. (2004). Issues in loanword phonology. Paper presented at Phonetic Society of Japan workshop, Tokyo University of Foreign Studies. 
Kubozono, H. (1996). Syllable and accent in Japanese: evidence from loanword accentuation. The Bulletin, Phonetic Society of Japan 211, pp. 71-82.

Kubozono, H. (2006). Where does loanword prosody come from? A case study of Japanese loanword accent. Lingua 116, pp.1140-1170.

Kubozono, H., J. Ito, in A. Mester (2009). Consonant Gemination in Japanese Loanword Phonology. The Linguistic Society of Korea (ed.), Current Issues in Unity and Diversity of Languages. Collection of Papers Selected from the 18th International Congress of Linguists [CIL 18]. Republic of Korea: Dongam Publishing Co., pp. 953-973.

LaCharité, D. in C. Paradis. (2005). Category preservation and proximity versus phonetic approximation in loanword adaptation. Linguistic Inquiry 36, pp. 223-258.

Lovins, J. B. (1975). Loanwords and the Phonological Structure of Japanese. Bloomington: Indiana University Linguistic Club.

Martin, S. E. (1987). The Japanese language through time. Yale: Yale University Press.

McCawley, J.D. (1968). The Phonological Component of a Grammar of Japanese. The Hague: Mouton.

Paradis, C. (1996). The inadequacy of filters and faithfulness in loanword adaptation. V J. Durand in B. Laks (ur.). Current trends in phonology: Models and Methods. Salford: ESRI, pp. 509-534.

Peperkamp, Sh. (2005). A Psycholinguistic Theory of Loanword Adaptations. V M. Ettlinger et al. (Ur.). Proceedings of the 30th Annual Meeting of the Berkeley Linguistics Society, pp. 341-352.

Peperkamp, Sh. in E. Dupoux. (2003). Reinterpreting Loanword Adaptations: The Role of Perception. In M. J. Solé et al. (Ur.). Proceedings of the 15th International Congress of Phonetic Sciences, pp. 367-370.

Poplack, S. in D. Sankoff (1984). Borrowing: The Synchrony of Integration. Linguistics 22, pp. 99-135.

Selkirk, E. (1978). On prosodic structure and its relation to syntactic structure. In T. Fretheim (Ur.), Nordic Prosody 2, pp. 111-140. Trondheim: TAPIR.

Selkirk, E. (1996). The prosodic structure of function words. In J. Beckman, L. Dickey, and S. Urbanczyk (Ur.), Papers in Optimality Theory. UMOP 18, pp. 439-469. Amherst: GLSA.

Silverman, D. (1992). Multiple Scansions in Loanword Phonology: Evidence from Cantonese. V Phonology 9(2), pp. 298-328.

Shibata, T. (1994). Gairaigo ni okeru akusento kaku no ichi. (O položaju naglasa v prevzetih besedah). V K. Sato (Ur.). Gendaigo Hoogen no Kenkyuu (Študije o novejših dialektih). Tokio: Meiji Shoin, pp. 338-418.

Shinohara, S. (2000). Default accentuation and foot structure in Japanese: Evidence from Japanese adaptations of French words. Journal of East Asian Linguistics 9, pp. 55-96.

Shinohara, S. (2004). Emergence of Universal Grammar in foreign word adaptations. V R. Kager, J. Pater in W. Zonneveld (Ur.). Constraints in Phonological Acquisition. Cambridge: Cambridge University Press, pp. 292-320.

Shoji, S., Shoji, K. (2014). Vowel epenthesis and consonant deletion in Japanese loanwords from English. Proceedings of the Annual Meeting on Phonology 2013.

Smith, J.L. (2006). Loan phonology is not all perception: Evidence from Japanese loan doublets. Vance, T.J. in Jones, K.A. (eds.). Japanese / Korean Linguistics 14. Stanford: CSLI, pp. 63-74.

Snoj, M. (2005). O tujkah in izposojenkah v slovenskem jeziku. Slovene Linguistic Studies 5, pp. 113-122.

Toporišič, J. (2000). Slovenska slovnica. Maribor: Obzorja.

Toporišič, J. in D. Reindl (2010). Slovenian. V Revue belge de philologie et d'histoire, tome 88, fasc. 3. Langues et littératures modernes, pp. 897-920.

Trubetzkoy, N. (1969 [1939]). Principles of phonology. Berkeley: University of California Press.

Yip, M. (2002). Perceptual influences in Cantonese loanword phonology. Journal of the Phonetic Society of Japan 6, pp. 4-21.

Yoshida, Y. (2006). Accents in Tokyo and Kyoto Japanese Vowel Quality in terms of Duration and Licensing Potency. SOAS Working Papers in Linguistics 14, pp. 249-264. 